Roche, J., Michel, R. \& Jouan, P. (1957). Ciba Foundation Colloq. Endocrin. 10, 168.

Rosenberg, I. N. (1951). J. clin. Invest. 30, 1.

Schultz, A. L., Sandhaus, S., Demorest, H. L. \& Zieve, L. (1954). J. clin. Endocrin. 14, 1062.

Sprott, W. E. \& Maclagan, N. F. (1955). Biochem. J. 59, 288.

Taurog, A., Briggs, F. N. \& Chaikoff, I. L. (1952). J. biol. Chem. 194, 655.
Taurog, A., Chaikoff, I. L. \& Tong, W. (1950). J. biol. Chem. 184, 99.

Vannotti, A. (1957). Ciba Foundation Colloq. Endocrin. $10,215$.

Wilkinson, J. H. \& Maclagan, N. F. (1955). Commun. 3rd Int. Congr. Biochem., Brussels, p. 122.

Wilkinson, J. H., Sprott, W. E., Bowden, C. H. \& Maclagan, N. F. (1954). Biochem. J. 56, 215.

\title{
The Determination of Ketone Bodies
}

\author{
BY P. A. MAYES* AND W. ROBSON \\ Department of Biochemistry, King's College, Strand, London, W.C. 2
}

(Received 25 October 1956)

In the determination of ketone bodies it is customary to convert acetoacetic acid and $\beta$-hydroxybutyric acid into acetone for estimation. This may be brought about during distillation (Shaffer, 1908-09; Shipley \& Long, 1938; Weichselbaum \& Somogyi, 1941) or by refluxing or heating in pressure bottles (Van Slyke, 1917; Greenberg \& Lester, 1944; Michaels, Margen, Liebert \& Kinsell, 1951). When distillation is employed preformed acetone plus acetoacetic acid may be estimated separately from $\beta$-hydroxybutyric acid in the one blood or urine filtrate; this is not possible when refluxing or pressure bottles are used. However, the latter methods permit greater reproducibility in the estimation of $\beta$-hydroxybutyric acid, since the aciddichromate reagent used for the oxidation is maintained at constant concentration.

The present method combines the advantages of both procedures by using a combined reflux and distillation apparatus. Acetone in the distillates is converted into the 2:4-dinitrophenylhydrazone, which is extracted with carbon tetrachloride and estimated colorimetrically by a modification of the method of Greenberg \& Iester (1944).

\section{MATERIALS AND METHODS}

Reagents. Sulphuric acid, $20 \mathrm{~N}$; potassium dichromate, $2.5 \%(w / v)$; freshly filtered 2:4-dinitrophenylhydrazine, $0.1 \%(\mathrm{w} / \mathrm{v})$ in $4 \mathrm{~N}-\mathrm{HCl}$; carbon tetrachloride; $\mathrm{NaOH}$, $0.5 \mathrm{~N}$; barium hydroxide, approx. $0.3 \mathrm{~N}$; zinc sulphate, approx. $5 \%(\mathrm{w} / \mathrm{v}) \quad \mathrm{ZnSO}_{4}, 7 \mathrm{H}_{2} \mathrm{O}(10 \mathrm{ml}$. of the barium hydroxide solution added drop by drop with phenolphthalein as indicator, should neutralize exactly $10 \mathrm{ml}$. of the $\mathrm{ZnSO}_{4}$ solution). Distilled water is used throughout the determination. All reagents are of A.R. grade.

* Present address: Division of Biochemistry, Department of Physiology, Royal Veterinary College, Royal College Street, London, N.W. 1.

\section{Preparation of standard solutions}

Acetone. A.R. acetone was redistilled three times, only the middle fraction boiling at $56.5^{\circ}$ being retained. Standard solutions were prepared by weighing up to $1 \mathrm{~g}$. of acetone in a stoppered tube and dissolving it in water. The possibility of loss of acetone due to volatilization was overcome by suspending the stoppered tube beneath water in a 21 . volumetric flask and removing the stopper by means of an attached thread. This solution was made up to 21 . and diluted as required.

Acetoacetic acid. Widmark (1920-21) found that acetoacetic acid in acid solution underwent complete decomposition to acetone, the determination of which could be used as a means of estimating quantitatively the acetoacetic acid. Accordingly, a solution of sodium acetoacetate, prepared by the method of Ljunggren (1924), was standardized with the present method.

$\beta$-Hydroxybutyric acid. The calcium-zinc salt of $\beta$ hydroxybutyric acid was prepared according to Shaffer \& Marriott (1913-14) and Blunden (1938). Colourless needles and plates were obtained (m.p. $247 \cdot 5-248 \cdot 5^{\circ}$ uncorr. with

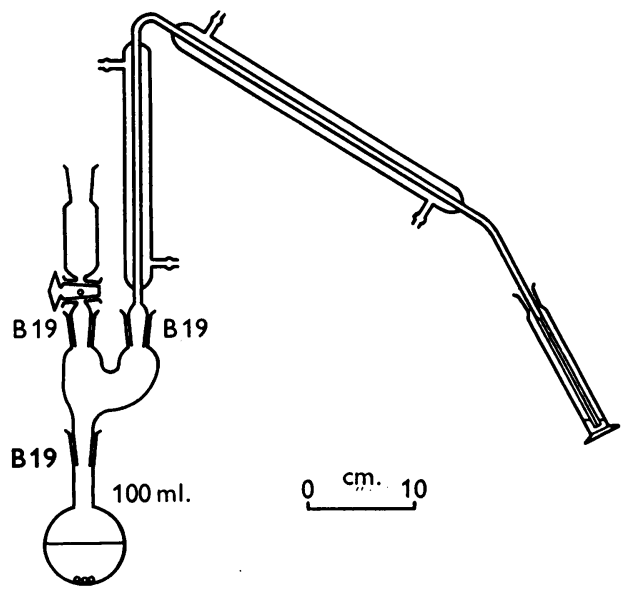

Fig. 1. Combined reflux and distillation apparatus. 
decomp.). Sodium $\beta$-hydroxybutyrate (British Drug Houses Ltd.), which the manufacturers claim to be $98 \%$ pure (Thin \& Robertson, 1952), was used also. Solutions were made from both preparations for use as standards.

Apparatus. An apparatus constructed from B19 standard ground-glass joints is employed (Fig. 1). The distillation tube (bore $8 \mathrm{~mm}$.) is fused to a length of capillary tubing (bore $2 \mathrm{~mm}$.) to form a delivery tube.

\section{Procedure for the estimation of acetone plus acetoacetic acid and of $\beta$-hydroxybutyric acid}

Deproteinization. Blood $(0 \cdot 1 \mathrm{ml}$.) is haemolysed by mixing it with water $(7 \mathrm{ml}$.) in a centrifuge tube $(15 \mathrm{ml}$.). The tube is stoppered and shaken. Barium hydroxide solution $(0.4 \mathrm{ml}$.) is added and the tube shaken to ensure complete mixing, followed by the addition of $\mathrm{ZnSO}_{4}$ solution $(0.4 \mathrm{ml}$.) and further vigorous shaking. The mixture is centrifuged and the supernatant liquid filtered through Whatman no. 44 filter paper. The filtrate is used for the estimation of ketone bodies.

Suitably diluted urine $(7 \mathrm{ml}$.) may be treated with the deproteinizing reagents in the same way as blood.

Distillation. The apparatus should be assembled with silicone high-melting-point grease between the joints. It is advisable to boil it out with water after assembly and before use each day. Into a $100 \mathrm{ml}$. flask, containing three small glass beads, is placed $\mathrm{H}_{2} \mathrm{SO}_{4}(8 \mathrm{ml}$.) and water $(50 \mathrm{ml}$.), followed by $5 \mathrm{ml}$. of deproteinized filtrate. A $5 \mathrm{ml}$. hypodermic syringe, fitted with a stop and calibrated to deliver within $\pm 0.1 \%$ may be used with advantage. This arrangement makes it possible to direct the filtrate into the reagents speedily and without loss on the sides of the flask. The flask is immediately fitted to the apparatus with cold water circulating through both condensers, and then boiled gently under reflux. After refluxing for $5 \mathrm{~min}$., the circulating water is drained from the reflux condenser, allowing the vapour to distil and collect in a $25 \mathrm{ml}$. stoppered-type graduated cylinder containing $1 \mathrm{ml}$. of 2:4-dinitrophenylhydrazine reagent. The rate of distillation is increased progressively and the graduated cylinder should be clamped so that the delivery tube dips beneath the surface of the reagent. When $5 \mathrm{ml}$. of distillate has collected, the graduated cylinder is lowered slightly to expose the delivery tube, which is washed externally with a fine jet of water $(4 \mathrm{ml}$.), and internally by allowing a further $5 \mathrm{ml}$. of distillate to collect in the cylinder. Immediately, distillation is stopped by circulating cold water through the reflux condenser. Potassium dichromate solution $(2 \mathrm{ml}$.) is introduced into the apparatus via the tap funnel, followed by water $(10 \mathrm{ml}$.), which should rinse into the apparatus any dichromate remaining in the funnel. After refluxing for $40 \mathrm{~min}$. a distillate is collected as described above. Boiling must be continuous throughout the procedure to avoid sucking back laboratory air. The first distillate is analysed for its acetone content and represents acetone plus acetoacetic acid. The second distillate contains the acetone derived from the oxidation of $\beta$-hydroxybutyric acid.

Colorimetric estimation of acetone. The distillate which has collected in the $25 \mathrm{ml}$. graduated cylinder is made up to exactly $15 \mathrm{ml}$. with water. Carbon tetrachloride $(6 \mathrm{ml}$.) is added from an automatic burette and the cylinder is stoppered and shaken mechanically for $150 \mathrm{~min}$. After it has separated, the supernatant acid solution is sucked off. Without shaking it, the cylinder is filled twice with water, which is sucked off each time; finally, $\mathrm{NaOH}$ solution $(9 \mathrm{ml}$.) is added. The solutions are shaken for a further $5 \mathrm{~min}$. and allowed to stand. When the carbon tetrachloride layer is perfectly clear the optical density is read in a spectrophotometer at 350 or at $410 \mathrm{~m} \mu$, depending on the concentration of acetone present. With the Spekker absorptiometer a violet filter (Ilford 600 or 601) should be used. Blank determinations are carried out with water in place of blood or urine. A calibration curve is obtained by similarly treating appropriate standard solutions of acetone. Complete analysis of solutions of pure $\beta$-hydroxybutyric acid shows that only $86 \%$ of the theoretical amount of acetone is obtained. Allowance must be made for this in calculating the results.

\section{Procedure for the estimation of total ketone bodies}

When the possibility of an error of up to $5 \%$ can be tolerated a determination for total ketone bodies may be carried out (see Results). Sulphuric acid $(8 \mathrm{ml}$.), water $(40 \mathrm{ml}$.) and blood or urine filtrate $(5 \mathrm{ml}$.) are boiled under reflux for $5 \mathrm{~min}$. Potassium dichromate solution $(2 \mathrm{ml}$.) and then water $(10 \mathrm{ml}$.) are added to the boiling mixture and refluxed for a further $40 \mathrm{~min}$. A distillate is collected which contains acetone derived from all ketone bodies. In calculating the results, the conversion of total ketone bodies into acetone is assumed to give a recovery of $91 \%$ based on the assumption that $\beta$-hydroxybutyric acid and acetone plus acetoacetic acid are present in the molar proportion of 2:1 (Weichselbaum \& Somogyi, 1941).

\section{RESULTS}

All results were obtained with the Spekker absorptiometer (Ilford 601 filter) unless stated otherwise.

\section{Colorimetric estimation of acetone}

In a preliminary experiment it was found that on distillation $99 \%$ of acetone present could be collected in the first $4 \mathrm{ml}$. of distillate and the remainder in the next $7 \mathrm{ml}$. The procedure of Greenberg \& Lester (1944) was modified so that $15 \mathrm{ml}$. of reagent, acetone distillate and washings was shaken with $6 \mathrm{ml}$. of carbon tetrachloride for extraction. To obtain reproducible readings it was necessary that the distribution of 2:4-dinitrophenylhydrazone and -hydrazine reached equilibrium between the aqueous-acid solution and the carbon tetrachloride. This condition was arrived at after shaking for $150 \mathrm{~min}$. at 180 vibrations $/ \mathrm{min}$.

Greenberg \& Lester (1944) showed that the amount of acetone-2:4-dinitrophenylhydrazone extracted by the carbon tetrachloride depended on the volumes and strengths of the fluids involved. As the acidity of the phenylhydrazine solution increased so the extraction of the hydrazone decreased. In the present work it was found that increased acidity shortened the shaking time required to reach equilibrium but increased the optical density of the blanks by causing more hydrazine to be extracted. The concentrations used 
in the method represent a balance between rapid extraction on the one hand and high blanks on the other.

Maximum absorption of acetone-2:4-dinitrophenylhydrazone occurred at $350 \mathrm{~m} \mu$, and a second absorption peak was found at $410 \mathrm{~m} \mu$. Present results agree with those of Lester \& Greenberg (1948), who found the absorption at $350 \mathrm{~m} \mu$ approximately four times that at $420 \mathrm{~m} \mu$. Readings obtained with standard solutions of acetone equivalent to $0-80 \mathrm{mg}$. $/ 100 \mathrm{ml}$. of blood showed that Beer's Law was strictly followed over this range. Reproducibility of readings was within $\pm 1 \%$. With $0.1 \mathrm{ml}$. samples the method is sensitive to $0.03 \mathrm{mg}$./ $100 \mathrm{ml}$. of blood, the Unicam SP. 500 spectrophotometer being used at $350 \mathrm{~m} \mu$.

\section{Distillation of acetone}

Shipley \& Long (1938) have reported a loss of $15 \%$ when acetone is distilled. Greenberg \& Lester (1944) and Michaels et al. (1951) criticized the use of distillation because of this risk. With the present apparatus and procedure it is possible to reflux and distil acetone without loss. A stemless dropping funnel was used so that no acetone was trapped on distillation. It was found that the capillary delivery tube (Fig. 1) forced the distillate to occupy the whole of the bore, ensuring complete washing out of acetone. It was essential for the condenser tube to be kept grease-free in order to obtain a regular flow of distillate.

Known quantities of acetone were refluxed for $10 \mathrm{~min}$. under the conditions previously described. Acetone in the distillates was estimated colorimetrically; the results are summarized in Table 1.

\section{Oxidation of $\beta$-hydroxybutyric acid}

Shaffer \& Marriott (1913-14), Van Slyke (1917) and Weichselbaum \& Somogyi (1941) showed that variations in concentration of sulphuric acid and potassium dichromate affected the final yield of acetone. High concentrations of either of these reagents diminished the yield of acetone, but, on the other hand, the reaction was prolonged if the concentrations were very low. In recent methods there is a marked lack of correlation between the conditions employed and the results obtained for the oxidation of $\beta$-hydroxybutyric acid. Weichselbaum $\&$ Somogyi (1941), using a reaction mixture of $60 \mathrm{ml}$. volume, obtained $85 \%$ conversion of $\beta$ hydroxybutyric acid into acetone in $40 \mathrm{~min}$. Greenberg \& Lester (1944), using the same concentrations of reagents, but in a much smaller volume of $3.6 \mathrm{ml}$. of solution, obtained $86 \%$ conversion and reported that the reaction was complete in $10 \mathrm{~min}$. Using approximately the same concentrations, Michaels et al. (1951) claimed $100 \%$ conversion when the reaction mixture was autoclaved in screw-capped bottles at $15-20 \mathrm{lb}$./in. ${ }^{2}$ pressure. On the other hand, Thin \& Robertson (1952), using the microrefluxing apparatus of Greenberg \& Lester could obtain only a $60 \%$ yield of acetone; alteration of the concentration of chromic acid, the time of oxidation or the concentration of $\beta$-hydroxybutyric acid failed to increase the percentage recovery.

To ensure reproducible results in the estimation of $\beta$-hydroxybutyric acid, the reagents must remain in constant concentration throughout the period of oxidation. In the present method, this has been achieved by : (i) refluxing the solutions; (ii) ensuring

Table 1. Recovery of ketone bodies (expressed as acetone equivalents)

\begin{tabular}{|c|c|c|c|c|c|c|}
\hline \multirow{3}{*}{ Material added } & \multirow[b]{2}{*}{ Medium } & \multirow{2}{*}{$\begin{array}{c}\text { Quantity of } \\
\text { material added } \\
\text { (range) } \\
\text { (mg./100 ml.) }\end{array}$} & \multicolumn{3}{|c|}{ Quantity of material recovered (\%) } & \multirow{2}{*}{$\begin{array}{l}\text { No. of } \\
\text { tests }\end{array}$} \\
\hline & & & Mean & Range & S.E. & \\
\hline & \multicolumn{6}{|c|}{ (a) Pure solutions } \\
\hline & Water & $11 \cdot 3-30 \cdot 8$ & $99 \cdot 8$ & $98 \cdot 5-101 \cdot 6$ & $0 \cdot 17$ & 14 \\
\hline $\begin{array}{l}\text { xybutyric acid } \\
\text {-Zn salt) }\end{array}$ & Water & $16 \cdot 0-31 \cdot 5$ & $85 \cdot 9$ & $85 \cdot 2-86 \cdot 8$ & $0 \cdot 16$ & 11 \\
\hline xybutyric acid & Water & $31 \cdot 6$ & $85 \cdot 75$ & $85 \cdot 5-86 \cdot 0$ & - & 2 \\
\hline \multicolumn{7}{|c|}{ (b) Blood and urine } \\
\hline & Blood & $14 \cdot 0-42 \cdot 5$ & $99 \cdot 6$ & $98 \cdot 7-100 \cdot 0$ & $0 \cdot 20$ & 9 \\
\hline & Urine & $24 \cdot 3-44 \cdot 9$ & $99 \cdot 6$ & $98 \cdot 2-100 \cdot 8$ & 0.21 & 9 \\
\hline $\begin{array}{l}\text { etic acid } \\
\text { ium salt) }\end{array}$ & Blood & $16 \cdot 5-50 \cdot 9$ & $98 \cdot 3$ & $97 \cdot 5-99 \cdot 3$ & 0.22 & 9 \\
\hline $\begin{array}{l}\text { etic acid } \\
\text { ium salt) }\end{array}$ & Urine & $24 \cdot 5-51 \cdot 8$ & $98 \cdot 1$ & $97 \cdot 2-98 \cdot 7$ & $0 \cdot 19$ & 9 \\
\hline $\begin{array}{l}\text { xybutyric acid } \\
\text { Zn salt) }\end{array}$ & Blood & $16 \cdot 1-42 \cdot 7$ & $99 \cdot 7 *$ & $98 \cdot 0-101 \cdot 3$ & $0 \cdot 27$ & 9 \\
\hline xybutyric acid & Urine & $14 \cdot 8-47 \cdot 3$ & $99 \cdot 7 *$ & $98 \cdot 6-100 \cdot 9$ & $0 \cdot 21$ & 9 \\
\hline
\end{tabular}

Acetone

$\beta$-Hydroxybutyric acid (as Ca-Zn salt)

$\beta$-Hydroxybutyric acid (as sodium salt)

\section{Acetone}

Acetone

Acetoacetic acid

(as sodium salt)

Acetoacetic acid

(as sodium salt)

$\beta$-Hydroxybutyric acid

(as Ca-Zn salt)

$\beta$-Hydroxybutyric acid (as Ca-Zn salt)

* The conversion factor $\mathbf{8 5 . 9} \%$ has been used in calculating this acetone equivalent (see text). 
an excess of reagents, so that the oxidation of $\beta$-hydroxybutyric acid and other reducing substances present in biological fluids does not influence their effective concentrations; (iii) adding the reagents to the reaction mixture as quickly as possible.

Because the conversion of $\beta$-hydroxybutyric acid into acetone is incomplete, the common practice of estimating 'total ketone bodies' as one entity leads to inaccuracy, since the assumption is made that the ratio of the fraction of $\beta$-hydroxybutyric acid to that of acetone plus acetoacetic acid is 2:1 (Weichselbaum \& Somogyi, 1941). Crandall (1940) has reported ratios as high as 15:1, and during the present work ratios have been found varying from $1: 1$ to $20: 1$. Accuracy can be attained only by estimating $\beta$-hydroxybutyric acid separately.

Time required for complete oxidation of $\beta$-hydroxybutyric acid. A series of replicate experiments was performed, with calcium zinc DL- $\beta$-hydroxybutyrate, in which the time of refluxing with potassium dichromate and sulphuric acid was varied from 10 to $75 \mathrm{~min}$. before collection and determination of acetone in the distillates. The results showed that 30-40 min. was required for completing the reaction under present conditions and they agree with those of Weichselbaum \& Somogyi (1941).

Percentage yield of acetone from $\beta$-hydroxybutyric acid. Aqueous solutions of different concentrations of calcium zinc DL- $\beta$-hydroxybutyrate were refluxed with acid dichromate for $40 \mathrm{~min}$. The acetone formed was distilled and determined. A mean recovery of $85.9 \%$ of the theoretical quantity of acetone obtainable from $\beta$-hydroxybutyric acid was found (Table 1). When the sodium salt of DL- $\beta$ hydroxybutyric acid (British Drug Houses Ltd.) was used as a standard, similar results were obtained, demonstrating that the low results of Thin \& Robertson (1952), who used a preparation from the same source, are unlikely to be due to its impurity.

\section{Application of the method to blood and urine}

Recovery experiments were carried out with standard solutions of ketone bodies added to blood and urine (Table 1). The mean recovery of acetone from blood and from urine was $99.6 \%$.

The results with sodium acetoacetate (Table 1) show an invariable loss of nearly $2 \%$ of the acetoacetate added. The mean recoveries of $98.3 \%$ (s.E. \pm 0.22 ) and $98.1 \%$ (s.E. \pm 0.19 ) for blood and urine respectively were significantly different from $100 \%(P<0.001)$. Subsequent work showed that the deproteinization technique was not at fault and that the presence of either blood or urine was necessary to cause the loss. In addition, the loss occurred only when the added acetoacetate was present as the sodium salt and did not occur with the ethyl ester.
When known quantities of calcium zinc DL- $\beta$ hydroxybutyrate were added to blood and urine a mean recovery of $99.7 \%$ (the conversion factor $85.9 \%$ being used) was obtained, which was not significantly different from $100 \% \quad(P \quad 0.4-0.2)$ (Table 1).

A series of estimations on samples of normal human blood was undertaken to show that the method did not give elevated values for the normal ketone-body level. The results, $0 \cdot 3-0 \cdot 6 \mathrm{mg}$. of total ketone bodies (expressed as acetone) $/ 100 \mathrm{ml}$, were of the same order of magnitude as the results of Weichselbaum \& Somogyi (1941) and Greenberg \& Lester (1944). The latter authors found it necessary to introduce an extra period of refluxing with stronger dichromate in order to oxidize interfering substances more completely; in the present method this was found to be unnecessary.

Replicate determinations for ketone bodies were carried out on $0.1 \mathrm{ml}$. portions of a sample of blood to test the reproducibility of the method. At a ketonaemic level of $40 \mathrm{mg}$. (expressed as acetone/ $100 \mathrm{ml}$.) the standard deviation for the estimation of acetone plus acetoacetic acid was $\pm 0.18 \mathrm{mg}$./ $100 \mathrm{ml}$. (12 determinations) and for the estimation of $\beta$-hydroxybutyric acid $\pm 0.16 \mathrm{mg} . / 100 \mathrm{ml}$. (9 determinations). These results were obtained with the Unicam SP. 500 spectrophotometer at $410 \mathrm{~m} \mu$.

\section{Interference}

Greenberg \& Lester (1944) concluded that sugars and lactic acid, on treatment with sulphuric acid and dichromate, did not yield substances reacting with 2:4-dinitrophenylhydrazine. In the present method, only volatile substances such as aldehydes and ketones are able to interfere. Experiment showed that acetaldehyde caused interference which could not be eliminated completely. Prolonged shaking with the standard quantity of sodium hydroxide for $40 \mathrm{~min}$. reduced the interference by half. When formaldehyde was treated similarly its interference was eliminated. Ethanol, which, if present, is distilled unchanged from acid solution in the acetone plus acetoacetic acid fraction, interferes only in the estimation of total ketone bodies by its reaction with the dichromate to form acetaldehyde.

When solutions of acetone-2:4-dinitrophenylhydrazone in carbon tetrachloride are shaken with sodium hydroxide solution, as described in the method, the fraction extracted by the alkali imparts a purple-red colour to this solution. On the other hand, the 2:4-dinitrophenylhydrazones of acetaldehyde and formaldehyde impart an orangered colour to the alkaline layer. The occurrence of this colour is an indication of the presence of these aldehydes. 


\section{SUMMARY}

1. A method is described for the accurate quantitative analysis of ketone bodies from small samples $(0 \cdot 1 \mathrm{ml}$.) of blood and urine.

2. The method is based on the conversion of all ketone bodies into acetone, on the reaction of acetone with 2:4-dinitrophenylhydrazine and on subsequent colorimetric determination of acetone2:4-dinitrophenylhydrazone in carbon tetrachloride.

3. A combined reflux and distillation apparatus has been designed which ensures reproducibility in the estimation of $\beta$-hydroxybutyric acid and allows the separate and direct estimation of acetone plus acetoacetic acid and of $\beta$-hydroxybutyric acid from one sample.

4. At a ketonaemic level of $40 \mathrm{mg}$. $/ 100 \mathrm{ml}$., the standard deviation of an individual reading is less than $\pm 0.2 \mathrm{mg} . / 100 \mathrm{ml}$.

\section{REFERENCES}

Blunden, H. (1938). Proc. Soc. exp. Biol., N.Y., 38, 466.

Crandall, L. A. (1940). J. biol. Chem. 135, 139.

Greenberg, L. A. \& Lester, D. (1944). J. biol. Chem. 154, 177.

Lester, D. \& Greenberg, L. A. (1948). J. biol. Chem. 174, 903.

Ljunggren, G. (1924). Biochem. Z. 145, 422.

Michaels, G. D., Margen, S., Liebert, G. \& Kinsell, L. W. (1951). J. clin. Invest. 30, 1483.

Shaffer, P. A. (1908-09). J. biol. Chem. 5, 211.

Shaffer, P. A. \& Marriott, W. M. (1913-14). J.biol. Chem.16, 265.

Shipley, R. A. \& Long, C.N. H. (1938). Biochem. J.32, 2242.

Thin, C. \& Robertson, A. (1952). Biochem. J. 51, 218.

Van Slyke, D. D. (1917). J. biol. Chem. 32, 455.

Weichselbaum, T. E. \& Somogyi, M. (1941). J. biol. Chem. $140,5$.

Widmark, E. M. P. (1920-21). Acta med. scand. 53, 393.

\title{
The Mechanism of Action of Mercurial Preparations on Transport Processes and the Role of Thiol Groups in the Cell Membrane of Renal Tubular Cells*
}

\author{
By A. KLEINZELLER AND J. H. CORT \\ Laboratory for Cellular Metabolism, Czechoslovak Academy of Sciences, Prague, \\ and the Institute for Cardiovascular Research, Prague
}

(Received 6 December 1956)

The powerful diuretic action of mercurial preparations and investigation of the mechanism of their action in vivo have led to the generally accepted view that these substances directly or indirectly interfere with the reabsorption of sodium chloride and water by the tubular cells of the kidney (Schwartz \& Wallace, 1951). It is also agreed that mercurial preparations exert their effect by inhibiting SH groups of some essential cellular enzymes (see, for example, Barron \& Singer, 1945; Barron, 1951), but no clear-cut evidence is so far available concerning the localization of their action and detailed biochemical mechanism. Mudge (1951) ubserved that mercuric chloride (and also meralluride, an organic mercurial) at appropriate concentrations in vitro, inhibits the uptake of $\mathrm{K}^{+}$ion and loss of water by slices of kidney cortex which have previously been leached in isotonic sodium chloride at $0^{\circ}$, without, however, affecting the oxygen uptake of the tissue. A statement to the same effect has been made by Robinson (1954).

* A preliminary account was presented at the International Conference on Nervous trophic and active transport, Prague, August, 1956.
These results appeared to suggest therefore that mercurials interfere with the active transport of electrolytes in kidney-cortex slices, some authors maintaining that the primary effect is on $\mathrm{Cl}^{-}$ion transport (Schwartz \& Wallace, 1951; Axelrod \& Pitts, 1952).

In this paper evidence is given for the view that mercurials interfere with the permeability of the membrane of tubular cells by increasing passive influx of $\mathrm{Na}^{+}$ion, $\mathrm{Cl}^{-}$ion and water into the cells, without interfering with the active extrusion of $\mathrm{Na}^{+}$ion. Furthermore, evidence will be presented suggesting that the state of $\mathrm{SH}$ groups of proteins of the cellular membrane is a controlling factor in permeability. No evidence was found suggesting a direct effect of mercurials on $\mathrm{Cl}^{-}$ion transport per se.

\section{METHODS}

The experimental procedure used has already been described in some detail (Cort \& Kleinzeller, 1956) and will only be summarized here. Unless otherwise stated, slices of kidney cortex of normal rabbits (the uppermost slice being rejected) were leached in $0 \cdot 154 \mathrm{M}-\mathrm{NaCl}$ at $0^{\circ}$ for $2.5 \mathrm{hr}$., and samples of slices (usually 100-200 mg. wet wt.) were then 